\title{
Microbial Ecosystem Therapeutics-4
}

National Cancer Institute

\section{Source}

National Cancer Institute. Microbial Ecosystem Therapeutics-4. NCI Thesaurus. Code C162187.

An orally available formulation consisting of a well-defined mixture of over thirty intestinal bacteria isolated from a healthy donor stool sample with potential immunomodulatory effects. Upon administration, the bacteria in microbial ecosystem therapeutics-4 (MET4) may help maintain adequate colonization of the gastrointestinal ( $\mathrm{Gl}$ ) tract and modulate the composition of the normal microflora. Upon colonization of the Gl tract, the probiotic bacteria form a protective barrier that helps maintain the integrity of the epithelial barrier. This will interfere with the attachment of pathogenic bacteria and other harmful substances, prevent inflammation and improve Gl function. Additionally, increased gut microbiota diversity and the presence of certain bacterial genera present in MET 4 may improve outcomes following immunotherapy, potentially via certain mucosal and systemic immune responses induced by the microbiome across the gut barrier. 